\title{
Experiencia del manejo de la pandemia de COVID-19 en población rural ambulatoria de la Sierra Sur de Oaxaca, México
}

\author{
COVID-19 pandemic experience of the management of outpatient rural population from \\ the Sierra Sur de Oaxaca, Mexico
}

\section{José Domínguez-Rodas', Sergio A. Ramírez-García², Ana R. Rincón-Sánchez",} Nory O. Dávalos-Rodríguez ${ }^{3}$, Melecio H. Juárez-Pérez ${ }^{2}$ y Carlos E. Cabrera-Pivaral**

${ }^{1}$ Servicios Médicos Profesionales, Particulares, A.C., Miahuatlán de Porfirio Díaz, Oaxaca; ${ }^{2}$ CA-UNISIS-10 Biología Molecular, Derecho y Nutrición Traslacional, Universidad de la Sierra Sur, SUNEO, Miahuatlán de Porfirio Díaz, Oaxaca; ${ }^{3}$ Departamento de Biología Molecular y Genómica, Centro Universitario de Ciencias de la Salud (CUCS), Universidad de Guadalajara, Jalisco; ${ }^{4}$ Departamento de Salud Pública, CUCS, Universidad de Guadalajara, Jalisco. México

A los editores:

Durante el periodo de marzo de 2020 a marzo de 2021, en Miahuatlán de Porfirio Díaz, Sierra Sur de Oaxaca, se atendieron 1034 pacientes ambulatorios adultos con COVID-19. Acudieron por fiebre, cefalea, disnea, disgeusia, anosmia y ataque al estado general. Como no se contaba al inicio en el medio rural con pruebas moleculares y serológicas para la COVID-19, se utilizó la aplicación COVID-19 Detector Flask $\mathrm{App}^{1}$, en la cual se introduce la fotografía de una radiografía de tórax o una tomografía y estima la probabilidad de COVID-19, la cual en el 93\% se correlacionó con el resultado de la prueba de reacción en cadena de la polimerasa en tiempo real (qRT-PCR). Otro marcador utilizado fue el enantema palatofaríngeo, patognomónico de SARS-CoV2, que correlacionó con la qRT-PCR en el $100 \%$ de los ca$\operatorname{sos}^{2}$. Estos permitieron diagnosticar la infección en los primeros 3-4 días de su inicio. El $52 \%$ de la población atendida fueron diabéticos tipo 2 , y en ellos se inició simultáneamente el control metabólico de la glucemia en 70-100 mg/dl. Los medicamentos con actividad antiviral disponibles para la infección fueron la ivermectina, la hidroxicloroquina y la azitromicina (Fig. 1). El 10\% de los casos presentó bronconeumonía y coinfección con virus
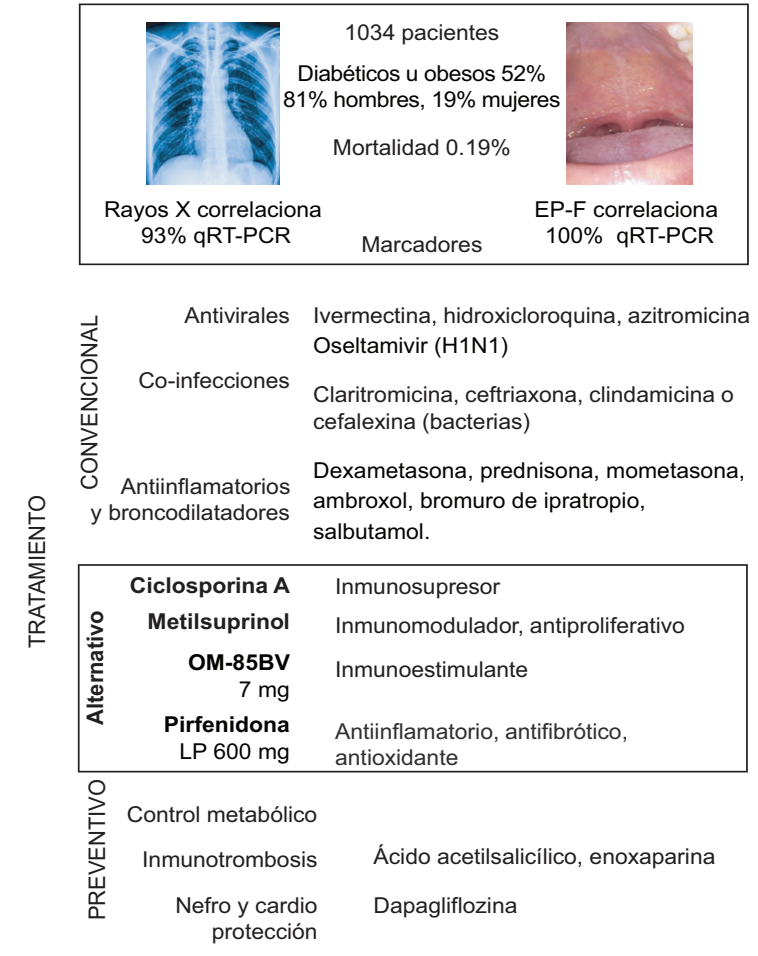

Figura 1. Resumen de los tratamientos para la COVID-19. Destacamos los marcadores, que permitieron hacer un diagnóstico temprano. A pesar de que más de la mitad de la población era diabética (alto riesgo), el inicio simultáneo con terapia antiglucémica redujo mucho las complicaciones y la mortalidad. Los inmunomoduladores (terapia alternativa) se administraron al no ver mejoría clínica después de 3 días con esteroides en pacientes con asma o hígado graso. EP-F: enantema palatofaríngeo; qRT-PCR: reacción en cadena de la polimerasa en tiempo real.

\section{Correspondencia: \\ ${ }^{*}$ Carlos E. Cabrera-Pivaral \\ Sierra Mojada 950, $P, 2^{\circ}$ nivel \\ Independencia}

C.P. 44340, Guadalajara, Jal., México

E-mail: cabrera_pivaral@prodigy.net.mx

0009-7411/O 2021 Academia Mexicana de

Fecha de recepción: 03-07-2021

Fecha de aceptación: 07-07-2021 DOI: 10.24875/CIRU.21000565
Cir Cir. 2020;88(3):133-134

Contents available at PubMed www.cirugiaycirujanos.com (http://creativecommons.org/licenses/by-nc-nd/4.0/). 


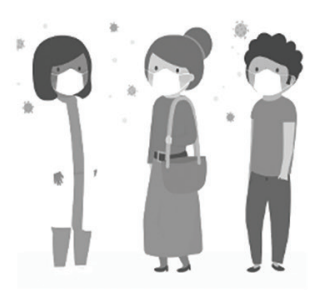

Pacientes ambulatorios
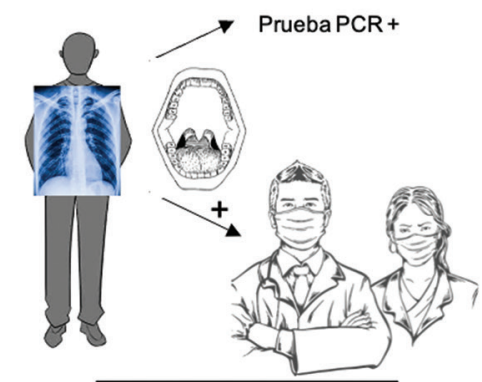

Diagnóstico temprano
Terapia convencional

Factores de riesgo

Terapia emergente

Firma de

consentimiento

informado

- Diabetes

- Obesidad

- Masculinos

Baja mortalidad

$0.19 \%$

Seguimiento

Resultado

Figura 2. Seguimiento de los pacientes con COVID-19 en el medio rural.

influenza $\mathrm{H}_{1} \mathrm{~N}_{1}$, que se manejó con oseltamivir, y el $5 \%$ coinfección bacteriana manejada con claritromicina, ceftriaxona, clindamicina o cefalexima. Para la tormenta de citocinas se contó con dexametasona, prednisona, metilprednisolona, ambroxol, bromuro de ipratropio y salbutamol. El $8 \%$ de los pacientes no tuvieron respuesta al tercer día de tratamiento y se usaron terapias emergentes, como inmunomoduladores, ciclosporina $A(5 \mathrm{mg} / \mathrm{kg} / 24 \mathrm{~h})$, inmunoestimulantes, metisoprinol y OM-85BV hasta por 7 días $^{3}$ (Fig. 2). La pirfenidona ${ }^{4}$ y el OM-85 BV (Broncho-Va$\mathrm{xom}^{\circledR}$ ) se usaron simultáneamente en tres pacientes que tenían asma crónica, hígado graso y colelitiasis, y a los 7 días de tratamiento se redujo la sintomatología, con un promedio de saturación de oxígeno del $96 \%$. Para la prevención de la inmunotrombosis se disponía de ácido acetilsalicílico y enoxaparina ${ }^{5}$. La nefrocardioprotección se realizó con dapagliflozina, por su capacidad para reducir el daño renal y el riesgo cardiovascular ${ }^{6}$.

En conclusión, se presenta la experiencia en el manejo de la pandemia de COVID-19 en un medio rural del Estado de Oaxaca, en donde a pesar de no contar con medios adecuados para la atención hospitalaria se logró tener una baja mortalidad basándonos en la detección oportuna mediante imágenes y marcadores clínicos.

\section{Agradecimientos}

Los autores agradecen a la Fundación Mexicana de Enfermedades Genéticas y Medicina Genómica, AC.

\section{Financiamiento}

Los autores recibieron financiamiento por parte de la Fundación Mexicana de Enfermedades Genéticas y Medicina Genómica, AC.

\section{Conflicto de intereses}

Los autores declaran no tener conflicto de intereses.

\section{Bibliografía}

1. Kaushik J. COVID-19 Detector Flask App based on chest X-rays and CT scans using deep learning. (Consultado 28/03/2021). Disponible en: https://towardsdatascience.com/covid-19-detector-flask-app-based-onchest-x-rays-and-ct-scans-using-deep-learning-a0db89e1ed2a.

2. Domínguez-Rodas J, Ramírez-García SA, Dávalos- Rodríguez NO, Cabrera -Pivaral CE. Enantema vesicular palatofaríngeo, un hallazgo temprano de Covid-19. Cir Cir. 2021;89(5):692-3.

3. Cao C, Wang J, Li Y, Li Y, Ma L, Abdelrajim M, et al. Efficacy and safety of OM-85 in paediatric recurrent respiratory tract infections which could have a possible protective effect on COVID-19 pandemic: a meta-analysis. Int J Clin Pract. 2021;75:e13981.

4. Seifirad S. Pirfenidone: a novel hypothetical treatment for COVID-19. Medical Hypotheses. 2020;144:1-5.

5. Carrillo-Esper R, Melgar RE, Jacinto SA, Tapia M, Campa AN. Alteraciones de la coagulación en COVID-19. Cir Cir. 2020;88:787-93.

6. Tejedor JA. Hemodynamic and renal implications of sodium-glucose cotransporter-2 inhibitors in type 2 diabetes mellitus. Med Clin. 2016;147:35-43. 